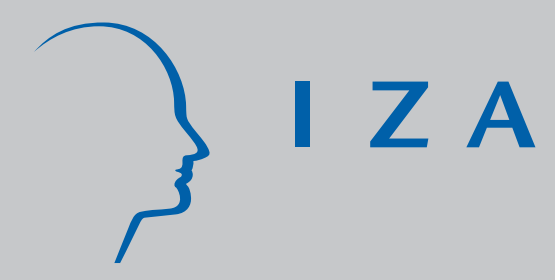

IZADP No. 2816

Does Community Property Discourage Unpartnered Births?

Olivia Ekert-J affe

Shoshana Grossbard

May 2007 


\title{
Does Community Property Discourage Unpartnered Births?
}

\author{
Olivia Ekert-Jaffe \\ Institut National d'Etudes Démographiques, France \\ Shoshana Grossbard \\ San Diego State University \\ and IZA
}

Discussion Paper No. 2816

May 2007

IZA

P.O. Box 7240

53072 Bonn

Germany

Phone: +49-228-3894-0

Fax: +49-228-3894-180

E-mail: iza@iza.org

Any opinions expressed here are those of the author(s) and not those of the institute. Research disseminated by IZA may include views on policy, but the institute itself takes no institutional policy positions.

The Institute for the Study of Labor (IZA) in Bonn is a local and virtual international research center and a place of communication between science, politics and business. IZA is an independent nonprofit company supported by Deutsche Post World Net. The center is associated with the University of Bonn and offers a stimulating research environment through its research networks, research support, and visitors and doctoral programs. IZA engages in (i) original and internationally competitive research in all fields of labor economics, (ii) development of policy concepts, and (iii) dissemination of research results and concepts to the interested public.

IZA Discussion Papers often represent preliminary work and are circulated to encourage discussion. Citation of such a paper should account for its provisional character. A revised version may be available directly from the author. 


\begin{abstract}
Does Community Property Discourage Unpartnered Births?*

This paper investigates the likelihood of an unpartnered birth as a function of laws regulating the division of joint property in case of divorce. Based on a rational choice model of marriage and assuming that on average women earn less than men, we predict that women are less likely to have an unpartnered birth when rules for the division of joint property are more advantageous to spouses with lower earnings. We derive more predictions regarding the effects of age, non-intact home, and religiosity, and the interaction between these variables and legal regime regarding divorce. We test our predictions with retrospective data from the Family Fertility Surveys collected in the 1990s. Most of our predictions are confirmed by a multi-country analysis for 17 legal regimes in 12 Western countries as well as single-country analyses for four countries. The results confirm most of our predictions. Our major findings are that the likelihood of an unpartnered birth is higher in countries that offer most women less access to joint property in case of divorce, and that this effect is weaker for teenagers than for women in their twenties.
\end{abstract}

JEL Classification: J12, J18, K3

Keywords: out-of-wedlock, cohabitation, fertility, divorce laws, joint marital property, unpartnered births

Corresponding author:

Shoshana Grossbard

Department of Economics

San Diego State University

San Diego, CA 92182-4485

USA

E-mail: shosh@mail.sdsu.edu

\footnotetext{
* We thank Bertrand Lemennicier for contributing to the decision-making model and Heather Joshi for suggesting the term 'Unpartnered Birth'. We are grateful for the assistance of Charlotte Aussillous, Cynthia Bansak, Arnaud Bringé, Emannuel Comolet, Guillaume Demonchy, Martine Deville-Velloz, and Howard Yourow. We received useful comments from Alessandro Cigno, Oystein Kravdal, and participants at presentations at the European Society for Population Economics conference in Verona, June 2006; Aarhus School of Business, and CES in Munich.
} 


\section{Introduction}

In recent decades family institutions in the West have undergone radical changes, including a switch from marriage to cohabitation and large increases in the proportion of children born out-of-wedlock (Lesthaeghe and Moors 2000). Children born out-ofwedlock include two very different categories of children: children born to unwed couples and children born to single mothers who don't reside with a partner. Children born to single mothers typically grow up with less of a father's presence in their lives than children born to an unwed couple (see Mincy and Oliver 2000). This can hurt children: relative to children raised by a couple, children raised by a single parent often achieve less in terms of school performace (McLanahan and Sandefur 1994, McLanahan and Sigle-Rushton 2004) and have higher rates of depression and crime participation (Hobcraft 1998, Sigle-Rushton, Hobcraft, and Kiernan 2005). ${ }^{1}$ This paper investigates the factors explaining whether a birth is unpartnered or occurs to a couple, married or not.

Unpartnered births have been explained by mother’s teenage status (Hawkes et al. 2004), low income (Wolfe et al. 2001), poor educational achievement (Ermish 1991, Ekert-Jaffe and Solaz 2001), parental divorce (McLanahan and Bumpass 1988, Kiernan and Cherlin 1999, Furstenberg and Kiernan 2001, Lichter et al. 1992, and Lehrer 2003), religiosity (Sweet and Bumpass. 1990), low gender ratios ${ }^{2}$ (Heer and GrossbardShechtman 1981, Guttentag and Secord 1983, and Willis 1999), and price and effectiveness of birth control (Akerlof, Yellen and Katz 1996, and Willis 1999).

\footnotetext{
${ }^{1}$ Even though divorce is the main factor behind the prevalence of lone motherhood, unpartnered births also contribute to that prevalence (Ermish 1991, Heuveline et al. 2003).

${ }^{2}$ Defined as the ratio of men to women in a marriage market. It is usually called 'sex ratio'.
} 
Even though we recognize that children and couple formation may often be the product of emotional decisions, not rational choices, we follow a long tradition of rational choice models of marriage (see e.g. Becker 1973, 1981 and Grossbard-Shechtman 1984), marriage versus cohabitation (such as Grossbard-Shechtman 1982 and Ekert-Jaffe and Sofer 1996), and out-of-wedlock childbearing (such as Akerlof, Yellen, and Katz 1996, Willis 1999, Wolfe et al. 2001, and Grossbard 2005). Also in the tradition of such economic models, we focus on women's financial advantages and disadvantages of having a child either alone or with a partner, while recognizing that the role of financial factors may be limited relative to the importance of social factors such as stigma. In particular, following Grossbard-Shechtman, Ekert-Jaffe, and Lemennicier (2002) we emphasize the financial impact of rules for the division of property at divorce.

Section II presents a classification of divorce laws according to degree of protection offered to women who earn less than their partner for the countries in our sample.

Section III develops the prediction that the more the law protects mothers in case of dissolution, the higher women's financial advantages of giving birth in couple, and the lower the odds of an unpartnered birth. We also present predictions regarding the effect of age, non-intact family of origin, and religiosity and the combined effects of some of these variables and rules for the division of property in case of dissolution.

After presenting our data and methods (Section IV), we test whether a low degree of community in laws regulating division of property at divorce has an impact on out-ofcouple births. Our results are based on the analysis of retrospective data on close to 30,000 women who gave birth to their first child between 1962 and around 1992 in 
twelve Western countries consisting of seventeen legal regimes. We first analyze pooled data and then perform single-country analyses of the effect of changes in law in four countries or provinces.

The results reported in Section V indicate that, as predicted, the less a country provides financial protection to divorcees who are non-principal earners, the more women are likely to have an unpartnered birth. In particular, we find that when we control for individual characteristics, (1) in countries with a high degree of Community Property—-such as Sweden--women are less likely to give birth without a partner than in Belgium or France, where Community Property is restricted to acquired assets; (2) relative to countries with restricted Community Property, unpartnered births are more common in common law countries such as the United States, where separation of assets is the norm; and (3) a switch from Common Law to Community Property is associated with a reduction in unpartnered births. Age appears to have a stronger effect on unpartnered births in countries with rules of division of property more advantageous to low-earning women. We also find that even though the overall trend in the countries we covered has been towards more unpartnered births, an early cohort of women born in the years 19461950 has exhibited unusually high rates of unpartnered births.

\section{Cross-Country Differences in Law}

The first two columns in Table 1 list type of Rules for Division of Property at Divorce (RDPD) for the countries and Canadian provinces in our sample, ranked by degree of legal protection expected by mothers in couple in case of separation (following Vogel 2002). Where countries recognize more than one RDPD we chose the one that is most commonly used. In three of our countries (Canada, Spain, and the U.S.) rules vary 
across states or provinces. Our data allowed us to separate Canadian provinces by RDPD, but we were not able to do so for the U.S.A. and Spain. Furthermore, RDPDs can vary over time. Four countries or provinces experienced changes in rules of division of joint property during the period we study. Two countries/provinces switched from common law to community property: New Zealand in 1976 and the Canadian Province of Ontario in 1978. Two countries switched from a no-divorce regime to a law recognizing divorce with some degree of Community Property: Italy in 1971 (its divorce law passed in December 1970) and Spain in $1981 .^{3}$

We created three categories capturing the degree of protection offered to women who consider having a child in couple without being the principal earner): low degree of community (Low Community or LC), medium degree of community (Medium Community or MC), and high degree of community (High Community or HC). Classification into MC or HC depends on the range of assets included in Community Property. The assets considered as part of Community Property are subject to a 50/50 division rule in case of divorce.

Countries with a low degree of community property (LC). These include

- three Common Law countries (New Zealand before 1977, Canada's Common Law provinces, and the U.S.A.). Even though some states in the U.S.A. follow Common Law and others follow restricted Community Property rules, it is easy for husbands/providers to move from Community Property states to Common Law states. We therefore classify the U.S.A. as a whole as a country that offers a limited degree of community property.

\footnotetext{
${ }^{3}$ Most of the countries in our sample offer similar benefits to partners who live together without marriage. Research has shown that even though it is more common for cohabitating women to earn more than their partner, a majority of both married and cohabiting women earn less than their partners.
} 
- Austria, where individuals maintain various separate assets at marriage. Goods for personal or professional use (such as an office or business equity) are excluded from a couple’s assets.

Countries with a medium degree of community property (MC). These are countries that apply Community Property only to assets a couple acquired after marriage. In our sample these countries include France and Belgium (Flanders only), the former West Germany, Finland, Quebec, the Canadian province of Ontario since 1985, Italy and Spain after they legalized divorce, and New Zealand after 1976.

Countries with a high degree of Community Property (HC). These are countries that have an extensive form of Community Property. In our sample, this includes Norway and Sweden, where most assets are considered as belonging to a couple, even if they were acquired prior to couple formation. However, it is common for heirs to stipulate that their inheritances will not be covered in Community Property.

We also distinguished a fourth category:

Countries with no divorce. While limiting individual freedom, rules that prohibited divorce offered some form of financial protection to women who earn less than their partner. This includes Italy and Spain before they legalized divorce in 1970 and 1981 respectively.

\section{A Decision-Making Model}

Assumptions. First, we assume that women make rational choices about whether to have a child alone or in couple. The more rationality can be presumed, the more the following model applies. The model is therefore more applicable when women are more educated, less religious, and beyond teenage. 
Second, while recognizing that there may be a stigma attached to lone motherhood, and that couple formation may entail numerous emotional or spiritual benefits, we focus on financial considerations related to separation or divorce. Our model applies best to individuals who expect that in a couple men earn more than women. In such cases, women may benefit financially from an equal division of joint property in case of dissolution. In all the countries in our sample men earn more than women in a majority of couples (see Blau, Ferber, and Winkler 2006).

Third, while recognizing that marriage offers some benefits not available to those who cohabitate out-of-wedlock, we ignore differences between married and unmarried couples and compare all mothers in couple around the time of birth to mothers who are single at that time. In part, this assumption reflects the increased tendency for Western countries to give the two kinds of couples the same legal treatment in case of separation or divorce.

The model. Define $Y$ as the present value of a woman's expected benefits of having a child in couple and $A$ as the present value of benefits accruing to unpartnered mothers. Both $Y$ and $A$ include a material and an emotional component, the material component being a function of a woman's earnings potential. Relative to $Y, A$ is more likely to include financial support by parents and governments.

Men influence women's choices to the extent that fathers' preferences and opportunities influence $Y$. $Y$ includes net expected financial benefits obtained from a partner while in couple $(B)$ and benefits accruing to mothers in case of dissolution $(D)$. To the extent that women expect their male partner to be the principal earner, both $B$ and $D$ will be non-negative. $Y$ also depends on the probability of dissolution $p_{d}$, as in: 
(1) $Y=f\left[\left(1-p_{d}\right) B+p_{d} D\right]$,

where $f^{\prime}>0$ as a function of $B$ and $D$. The difference

(2) $R^{*}=A-Y$

is defined as a latent variable representing the net benefit associated with having an unpartnered birth versus a child in couple; it is unobserved, but we observe $R$, the decision to have an unpartnered birth. We assume the decision rule:

(3) $\mid \begin{aligned} & R^{*}>0 \Rightarrow R=1 \\ & R^{*}<0 \Rightarrow R=0\end{aligned}$

This rule implies that if the net benefits of having an unpartnered birth exceed the net benefits of having a child in couple, a woman will have an unpartnered birth. Combining equations 1 and 3 gives:

(4) $R^{*}=A-f\left[\left(1-p_{d}\right) B+p_{d} D\right]$.

Assuming that the probability of divorce is given, we obtain the following partial derivative according to post-divorce benefits $D^{4}$ :

(5) $\partial R^{*} / \partial D=-f^{\prime} p_{d}<0$;

Given that the value of an unpartnered birth $R^{*}$ and the likelihood of an unpartnered birth $R$ are expected to move in the same direction, we thus predict that ceteris paribus, the higher post-divorce benefits $D$, the higher $Y$, and the lower the probability of an unpartnered birth. Benefits $D$, the benefits of giving birth in couple in case of separation, are partially a function of the rules of division of property in case of divorce or separation. The higher share of the combined property that the law offers

\footnotetext{
${ }^{4}$ There is an extensive economic literature, starting with Becker (1981), that discusses whether divorce laws affect the probability of divorce.
} 
women who separate from a partner who earns more than them, the higher the expected $D$ payment, and the lower the predicted probability of an unpartnered birth.

The more a couple's property is considered community property, the higher the expected $D$ for women in case of dissolution from partners earning more than them. To the extent that a majority of women earn less than men, we predict that the higher the degree of community of marital property in rules for division of property at divorce (RDPD), the lower the probability of an unpartnered birth. This implies that relative to MC countries, unpartnered births will be more common in countries and provinces that don't have Community Property laws such as the LC Common Law countries, and that such births will be less common in HC countries such as Norway and Sweden than in MC countries such as France and Germany. These and other predictions are summarized in Table 2.

Simple cross-country correlations provide some support to these predictions. It can be seen from Table 1 that Austria and countries with a division of property based on common law (which we categorized as LC) exhibit high rates of unpartnered births. In contrast, Sweden, a HC country, has a low percentage of unpartnered births. Low percentages of unpartnered births are also found in countries that traditionally made divorce illegal--Italy and Spain-and later switched to a MC rule. However, the correlation is not perfect. For instance, Norway, a HC country, has a relatively high percentage of unpartnered births.

A quick look at changes over time in New Zealand also supports our prediction. New Zealand exhibited a rate of unpartnered births as high as $15 \%$ before instituting 
Community Property. After it adopted an MC system, its unpartnered births for the period 1976-1995 fell to 9\%.

Interaction of $D$ and Other Variables. The more women are rational and the lower their discount rate, the more we expect an effect of legal regime on the probability of an unpartnered birth. Teenagers tend to be less rational and have a higher discount rate. ${ }^{5}$ Teenage women can also expect lower benefits $D$ in case of separation or divorce. For both of these reasons, we predict that the sign of the interaction term TEENAGER IN LC COUNTRY will take the opposite sign (negative) of the (positive) sign of the main effect of LC regime. ${ }^{6}$

Religiosity may reduce unpartnered births if religious women have fewer premarital relations. However, it may increase unpartnered births if they have fewer abortions. Which of these effects dominates may vary with the surrounding cultural and legal environment. The existing evidence is mixed. Within a given country, evidence for the U.S. shows that religious practice is negatively correlated with adolescent sexual activity (Thornton and Camburn 1989, Murry 1992, and Kirby 1999) and premarital relations, regardless of age (Beck et al 1991). However, the cross-country correlation is not clear: the most religious country in our sample (the U.S., see Table 3) has relatively high levels of unpartnered births, whereas in Italy and Spain, countries with high religiosity during most of the period we study, have very low levels of unpartnered births. In Spain women who grew up with a religious mother also have fewer children in marriage (see Branas-Garza and Neuman 2007).

\footnotetext{
${ }^{5}$ Nevertheless, even the childbearing decisions of teenagers seem to indicate some rationality, as shown by Wolfe et al (2001).

${ }^{6}$ To the extent that teenagers can expect a higher divorce probability, they would be more influenced by legal regime, but we expect this effect to be dwarfed by the other two considerations leading us to predict that the effect of LC will depend on teenage status.
} 
To the extent that religiosity reduces $R$ by discouraging premarital relations, we expect more religious women to be more responsive to financial incentives that discourage unpartnered births such as favorable divorce rules. In this case both religiosity and the interaction between a high degree of community and religiosity will have negative effects on $R .^{7}$ To the extent that religiosity encourages $R$ due to the lower abortion rates of religious women, the effect of religiosity on $R$ and the effect of the interaction between favorable divorce rules and religiosity on $R$ are both expected to be positive. Either way, the simple effect of religiosity on unpartnered births and the combined effect of religiosity and favorable divorce rules are predicted to go in the same direction.

In addition, we also obtain the following partial effect of $B$ assuming that $p_{d}$ is constant:

(6) $\partial R^{*} / \partial B=-\left(1-p_{d}\right) f^{\prime}<0$; we thus predict that ceteris paribus, the higher the marital benefits $B$ that women expect while in couple, the higher $Y$, and the lower the probability of an unpartnered birth. The more men value having a child in-couple and the higher their demand for women as mothers, the more they are willing to pay for it, and the more women are likely to avoid having an unpartnered birth. ${ }^{8}$ We expect teenagers and women from non-intact homes to be less in demand in the markets for dating and marriage. The ensuing lower values of $B$ offer an additional reason why teenagers have higher rates of unpartnered births. This also helps explain why women who grew up with single parents have a higher probability of unpartnered birth.

\footnotetext{
${ }^{7}$ Alternatively, religious and legal institutions may be intertwined, and countries that offer less financial protection to women at divorce may also have religious organizations that offer less support to women trying to avoid premarital relations.

${ }^{8}$ For more on Demand and Supply analysis of marriage markets see Grossbard-Shechtman (1984) and Choo and Siow (2006).
} 
Assuming that $D$ and $B$ are given, we get the partial effect:

(7) $\partial R^{*} / \partial p_{d}=-(D-B) f^{\prime}>0$. It follows that to the extent that the present value of in-marriage benefits $B$ exceeds the present value of benefits at divorce $D$, i.e. $B-D>0$, $Y$ will be a negative function of the probability of divorce $p_{d}$. We thus predict a positive association between divorce probability and the probability of an unpartnered birth. This gives us an additional reason to expect that women from non-intact families, who are more likely to expect that their own partnership will eventually dissolve, will be more likely to have an unpartnered birth. It has been shown that growing up with divorced parents in a non-intact family is expected to be associated with a higher likelihood of unpartnered birth (see e.g. Kiernan and Cherlin 1999 and Mincy, Grossbard and Huang 2005). ${ }^{9}$

We expect that one particular birth cohort, the first baby-boomers born right after World War II in the years 1946-1952 and characterized by a low gender ratio, will have more unpartnered births. According to Heer and Grossbard-Shechtman (1981) and Guttentag and Secord (1983) this cohort faced particularly unfavorable marriage and dating market conditions and, consequently, experienced more rapid growth in out-ofwedlock births than previous cohorts. Grossbard-Shechtman and Granger (1998) show that in the U.S. this cohort of women experienced more rapid increases in labor force participation than other cohorts, another aspect of these women's low value in marriage markets and possibly low Y.

During the period covered here, most European countries experienced a trend towards a substantial increase in unmarried cohabitation and unpartnered births that

\footnotetext{
${ }^{9}$ There is even more evidence regarding the effect of non-intact upbringing on the probability of an out-ofwedlock birth: see e.g. McLanahan and Bumpass 1988, Lichter et al. 1992, Kiernan and Cherlin 1999, Furstenberg and Kiernan 2001, and Lehrer 2003.
} 
Lesthaege and Moors (2000) have described as part of the second demographic transition, so we expect the time trend to be positive.

We expect that women out of the labour force have a higher ratio of $Y$ to $A$ than women who are employed, and that they therefore are less likely to have a child without a partner. Mother's low education has been associated with a higher likelihood of an unpartnered birth $R$ (see Ermish 1991 and Ekert-Jaffe and Solaz 2001). To avoid endogeneity, we will measure labour force attachment and educational level at the onset of pregnancy, while measuring whether a woman is in couple either at birth or right before birth.

\section{Data and Methods}

We perform two kinds of analysis: pooled cross-country analysis and analysis for individual countries and provinces that changed rules of division of marital property. In either case, our demographic data were drawn from the common core of the Family Fertility Surveys (FFS), retrospective data that were collected in the mid-1990s for women aged 15-59 in 24 industrial countries of the U.N. Economic Commission for Europe (UNECE; see Festy and Prioux 2002). After exclusion of ex-communist countries we are left with data from twelve countries: Austria, Belgium (Flanders), Canada, Finland, France, (the former West) Germany, Italy, New Zealand, Norway, Spain, Sweden, and the United States. These twelve countries correspond to seventeen legal regimes, for Italy, New Zealand and Spain are observed under two separate legal regimes, and Canada consists of three legal regimes: Quebec (MC all along), Ontario under MC (after 1985), and the LC regimes in Ontario until 1978 and the rest of Canada all along. ${ }^{10}$

\footnotetext{
${ }^{10}$ In our multi-country analysis we drop years of transition from one legal system to another in those countries that experienced a legal change that did not apply immediately. We dropped years of transition
} 
We focus on first births (most unpartnered births are first births) and measure marriage and cohabitation three months prior to birth in one set of cross-country regressions and in our single-country analysis. We also estimate multi-country regressions in which marriage and cohabitation were measured at the time of birth. ${ }^{11} \mathrm{We}$ limit our multi-country samples to women who were born in the years 1945-1970 and who gave birth in the years 1963-1992. However, our separate analyses for New Zealand, Ontario, and Italy include a wider range of age groups. In order to test the effect of a change in law on comparable women who would possibly have a child in or out of couple before and after a legal change, we need a period that is sufficiently long to provide us with a post-change sample comparable to the pre-change sample. This includes comparable age groups. ${ }^{12}$

In addition to a dummy for "teenager", all our models include a variable "mother older than $29^{\prime 13}$, mother's age at birth and the square of age centered at its sample mean (23 years). ${ }^{14}$ Mother's birth year is the difference between child's year of birth and age of the mother at birth. Therefore, collinearity results if we include all three variables. We

\footnotetext{
between legal regimes in Ontario, Canada (these are years 1978-1984) and in Italy (years 1971-1974). In Spain and New Zealand there was no transition: the legal change was instituted immediately.

${ }^{11}$ We also estimated regressions where marital status was measured at pregnancy and six months prior to birth. The results were identical to the results for marital status measured three months before birth.

${ }^{12}$ In our analysis of the effect of legal change in New Zealand the oldest women are born in 1936, and in our separate analysis of Ontario, Canada, the oldest women are born in 1941. Italy changed its law in December 1970 when the oldest women in the sample were 24 years old. We don't include mother's age in our regression for Italy given that we have so few observations of unpartenered births. This helps explains why the log likelihood ratio is lower for Italy.

${ }^{13}$ The literature does not offer clear evidence on the net effect of older age on $R$

${ }^{14}$ We thus conceive of the function of unpartnered births and age as fitting a parabolic curve, with higher values of unpartnered births at both extremity of the age scale: teens and over 29 . We chose the quadratic model after experimenting with a number of alternative models, including a model with all categorical values of mother's age at child's birth -under 18, 19-20, etc.--and a spline model. The quadratic form is more parcimonious and fits the data better according to the AIC and Schwarz criteria. For a justification for a quadratic function of age in similar cases, see Grossbard-Shechtman (1993; Chapters 4 and 10).
} 
opted to control for mother's age and child's year of birth, interpreting the latter as a time trend.

The effect of mother's cohort (birth year) on the probability of an unpartnered birth can be inferred from the difference between child's year of birth and mother's age at birth.

A basic pooled model of the likelihood of an unpartnered birth, $R$, (Model 1) was estimated with the following explanatory variables: dummies for country's legal system, child's year of birth, a dummy for mother born in 1946-1950, age, centered age square, a dummy for mother older than 29, and four interaction terms between mother age dummies and legal system dummies.

We also estimated Model 2, an augmented model that is identical to the basic model, except for also including information on whether a woman's parents had divorced when she was 15 years old, and an interaction term between parental divorce and legal regime. We consider parental divorce as exogeneous to a woman's decision to have a child with or without the presence of a partner. This model was estimated for the ten countries and 14 RDPD for which we also have information on parental divorce.

Model 3 is the same as Model 2, but in addition the mother's level of religiosity and an interaction term between religiosity and legal regime were included. This model was estimated for the eight countries, corresponding to twelve legal regimes, for which we have information on parental divorce and religion: all countries except Belgium, France, New Zealand, and Norway.

Finally, we estimated Model 4, which is the same model as Model 3, except for the addition of education dummies, number of siblings, and work and study status 
dummies. This model was estimated for the seven countries, corresponding to nine RDPDs, for which we have information on all the variables: Austria, Finland, (the former West) Germany, Italy, Spain, Sweden, and the United States.

We experimented with a quadratic function of education, but it was difficult to use a continuous education variable given the cross-country differences in education systems and age at graduation from high school. ${ }^{15}$ Instead, we include two dummies-some college and college or more- that are comparable across the different countries in spite of the diverse educational systems (see also Dourleijn et al. 2002). These variables take account of age at completion of education, the highest grade attended, the current age at first birth, and an external source of distribution of age at school completion. ${ }^{16}$

Table 3 presents means and variances for the variables used in the empirical models. We present country averages as well as averages for all twelve countries and for the sample of seven countries.

\section{Methods.}

The logit method is most appropriate when considering women’s two-way choice between giving birth with or without a partner, given that they are having a child. In this study we are not interested in studying the timing of birth or couple formation, but whether a couple is formed around the time of birth or not. ${ }^{17}$ We estimate logit regressions in both our pooled models and our single-country analyses.

\footnotetext{
${ }^{15}$ For instance, in the USA it is illegal to drop out of school before age 18. In contrast, in Austria, Italy and Spain, there is a large population of respondents who completed school by age 16, especially among older cohorts.

${ }^{16}$ More precisely, our categories are school completion at ages 19-23 with (some) college level attended, and school completed after age 23 or graduate education, the reference group being those who completed school before age 19 with a maximum of high school level.

${ }^{17}$ Other studies, including for instance Ermisch (1991) and Ekert et al. (2002), have modeled a single woman's chance of having a child in couple using hazard models.
} 
Our Pooled Cross-Country regressions were weighted to take account of the different sample sizes and sampling methods. The estimated variances associated with macro variables (dummies for RDPD and Cohort) were corrected given that they are mechanically smaller than the variances of individual characteristics (Moulton 1990).

We also estimate Single-Country regressions for each country or province that experienced a legal change during the period studied here. In 1976 New Zealand abandoned Common law in order to adopt an MC regime. Ontario, a major Canadian province, did the same in 1978. Our sample also includes two countries that switched from 'no divorce' to a MC regime: Italy in 1971 and Spain in 1981. In each of these countries, we have few cases of unpartnered births and this leads to imprecise estimates. As a result, the individual country regressions that we present in Table 6 don't include all the variables included in the multi-country regressions of Tables 4 and 5 . If we get significant effects of legal change despite the small sample sizes, this is strong evidence for our model.

For each of the four countries that experienced a legal change we estimated the likelihood of an unpartnered birth, $R$, with a time trend and a dummy for the country's legal system up to one year after the law change. We selected the period of observation that has the largest possible range centered in the year of the change of rule. For the variation in the probability of an unpartnered birth to reflect the effect of a change in law and not a difference in mother's age, we have to make sure that the age composition of our sample does not vary too much. This is especially important given that the likelihood of an unpartnered birth varies strongly with age (as is apparent from the multi-country results presented below). 


\section{Regression Results}

Pooled Cross-Country Analysis. Tables 4 and 5 report the results of our logit regressions estimated for four samples of Western women, depending on the specification. In Table 4 partnership is measured three months prior to birth whereas in Table 5 it is measured at birth. Note that results in bold have the highest level of significance.

Effect of Rule of Division of Property at Divorce (RDPD). We find evidence for our major prediction: the lower the degree of community in a country's divorce laws, the higher women's likelihood of having an unpartnered birth. We find that women living in countries with medium levels of Community Property (MC) have a lower likelihood of giving birth without a partner than women in countries with low levels of Community Property (LC). It appears from Tables 4 and 5 that the effect of LC (low community) is robust to the introduction of individual economic and social characteristics and does not depend on the point in time at which partnership is defined. Furthermore, it appears from our seven- and eight-country models in both tables that in countries with a high degree of community in joint property (HC) women have a significantly lower percent of unpartnered births than in countries with MC (medium levels of Community Property). This result is also found for the 10-country model in column 4 of Table 4 . Most unlikely to give birth without a partner were women in countries where divorce was illegal, a finding significant at the highest level.

Effect of cohort, trend, and age. All our models indicate that women born in the years 1946-52, right after WWII, are more likely to have an unpartnered birth than women born at other times, and this finding takes the highest level of significance. This 
reflects the effect of low gender ratios, given that rapid increases in number of births followed a period of low births, and age difference at marriage did not change much. The higher likelihood of unpartnered births thus reflects the particularly unfavorable marriage market conditions that women of this cohort have faced. This post-WWII baby-boomer effect is striking, for it contrasts with the upward trend in unpartnered births that possibly indicates a decreasing stigma associated with an unpartnered birth. This positive trend is statistically significant in the 12-country and 10-country models in Tables 4 and 5, but not the 7-country models. ${ }^{18}$

In all our models we find that relatively to birth patterns for women in their twenties, unpartnered births are more common among women who are younger than 20 (including teenagers) and older than 29. This appears both from the quadratic term, a function of the age at birth minus 23 , and from a dummy indicating whether a woman is older than 29. It appears that between ages 20 and 29 the benefits of age exceed the disadvantages of age, but the opposite is true after age 29 (possibly a function of the prospects of reduced fecundity). Note that a negative effect of mother's age at birth has implications for cohort effects. Controlling for child's birth year, for the entire period we study (1961-1995), younger women (who also belong to younger cohorts) appear to be more likely to have an unpartnered birth.

We had predicted that RDPDs will have less impact on unpartnered births among teenagers than among more mature women. We find that indeed, relative to the main effects of RDPD, the interaction between 'Younger than 20' and the HC dummy goes in the opposite direction of the main effects of HC. The interaction term with HC has a

\footnotetext{
${ }^{18}$ The 7-country models include some countries with consistently high rates (the U.S. and Austria) and consistently low rates of (Sweden, Italy, and Spain) of unpartnered births throughout the period.
} 
magnitude that exceeds that of the main effect to such an extent that in HC countries the likelihood of an unpartnered birth among teenagers is even higher than that found in MC countries (but it is smaller than the rate of unpartnered births among teenagers in LC countries).

It can be seen from Tables 4 and 5 that the effect of 'older than 29' on an unpartnered birth is larger in a MC country than in a LC country (the sign of the interaction with LC is negative). That the interaction goes in the opposite direction of the main effect indicates that the higher protection offered by a more advantageous RDPD means less to women having a first birth past age 29 than to women doing so in their twenties. This finding is consistent with a worsened marriage market position for women past age 30 (leading to lower benefits from marriage $B$ and value of divorce settlement $D$ ) and with higher proportions of older women bypassing traditional gender roles and supporting a child without living with a partner. It is possible that for women receiving no positive benefit $B$ during marriage, higher degrees of community property are a drawback, for in this case they protect men more than women.

All the models including the variable 'non-intact family of origin' support our prediction that parental divorce is associated with a higher likelihood of an unpartnered birth. ${ }^{19}$ We also find a negative impact of non-intact family background on the behavioural influence of Low Community in our ten-country model in both tables, and a weak result in the same direction in the eight-country model. We thus find that three groups of women with characteristics that are not considered appealing in markets for

\footnotetext{
${ }^{19}$ This finding has a lower level of significance for the 7-countries sample, possibly the result of the exclusion of Canada. Canada experienced rapid increases in divorce rate towards the end of our sample years. It is possible that therefore information on parental divorce is not as a good an indicator of women's divorce prospects in Canada than in other countries included in the sample.
} 
marriage and cohabitation (from the perspective of potential husbands/providers) have a higher likelihood of unpartnered birth: teenagers, women past age 30, and children of divorce.

It appears from the full seven-country model in Tables 4 and 5 that unpartnered births are most likely to occur among women who completed their studies before age 19 and don't have more than a high school education. We also find that any education beyond high school is associated with a lower $R$ and that the impact of a post-graduate education is not significantly different from that of some college education. The sevencountry models indicate that women who were students before giving birth are more likely to have a child alone $e^{20}$ and that women with one to three siblings are less likely to be mothers without a partner than women who either have no siblings or came from a family of five or more children. ${ }^{21}$

It is apparent from the eight-country models in both tables that observant women (attending a religious service at least once a week) are less likely to have an unpartnered birth. This indicates that for this group of countries, the discouraging effect of religion on extra-marital relations dominates the effect of religion on $R$ via prohibition of abortions. However, this effect does not hold for LC countries, according to both the eight-country model (column 5) and the seven-country model (column 6): the interaction term with LC

\footnotetext{
${ }^{20}$ We have a number of possible explanations for this: students may be more willing to challenge norms; students tend to have a lower income and therefore are more likely to qualify for government benefits if they have a child without a partner; students are more likely to receive help from their parents; or couples including a student are more unstable.

${ }^{21}$ This may indicate either that women with no siblings or from a very large family are more interested in having a child without a partner or that women with such background are considered as less attractive potential co-parents by men willing to act as primary earners (leading to lower offers of $B$ ). In addition, very large families and one child families tend to be associated with lower income.
} 
is positive and of a magnitude similar to that of the main effect. ${ }^{22}$ This confirms the prediction that religiosity and the interaction term "religiosity in a LC country" will have opposite signs. Our prediction regarding the interaction "religiosity in a HC country" was not confirmed.

Single-Country Analysis. Table 6 reports the results of our logit regressions estimated for each of the four countries/provinces that experienced a legal change. The regressions all include a dummy for the old rule for division of property at divorce (if there was divorce). In the case of New Zealand and the Canadian province of Ontario, prior to the switch to an $\mathrm{MC}$ regime, there were more unpartnered births. In the case of Italy and Spain, prior to the legalization of divorce and the adoption of an MC regime there were fewer unpartnered births. Even though the sample sizes are modest, all the RDPD dummies are significant.

Table 6 also offers support for our prediction regarding the effect of an interaction between teenage and RDPD. The sign of the interaction of teenager and previous rule is negative in the case of LC, which is a finding we also obtained with the multi-country sample. The sign of the interaction of teenager and previous rule is positive in the case of 'no divorce'. In both cases, the interaction takes the opposite sign from that of the direct coefficient of 'previous RDPD', indicating that the rational model presented here applies more to women who are twenty or older than it does to teenagers.

Models' Robustness. All the models we reported-whether the multi-country ones reported in table 4 and 5 or the single-country model reported in Table 6 - confirm our principal predictions: the more generous the RDPD to women who are non-principal

\footnotetext{
${ }^{22}$ Interestingly, if we don't include the interaction between religiosity and LC, the effect of religiosity disappears.
} 
earners, the fewer unpartnered births, and this is more likely to hold for women above age 20 than for teenagers. We tested the robustness of the single-country models by simulating artificial changes in law for the same countries. Dummies that were not in accordance with the real date at which a change of RDPD was introduced did not yield coefficients significantly different from zero.

To test the robustness of our multi-country models, we tested whether our RDPD variables were picking up other national characteristics and estimated models that included other country-level variables correlated with our RDPD dummies. Given the small number of countries in our sample, we avoided including too many country-level variables at once. ${ }^{23}$ When we included average country-level parental divorce rate (calculated from our data about women's parental divorce) in addition to the variables in Table 4, the LC effects, including interaction terms, continued to hold, but the HC effect disappeared. The disappearance of the HC effect in this unreported regression is related to the fact that Sweden, the only high Community Property country included in our seven- and eight-country models, has a relatively high divorce rate, and that, controlling for the positive effect of individual parental divorce, country-level parental divorce has a significantly negative effect on the likelihood of an unpartnered birth.

We also estimated a model similar to the model in column 6 in Table 4, but including country-level average religiosity (as estimated from our data). We continue to obtain a large and significantly positive effect of Low Community Property (LC). The higher the country-level religiosity, the higher the likelihood of an unpartnered birth. This

\footnotetext{
${ }^{23}$ Furthermore, multi-level analysis modeling two levels (country and individual, see Goldstein 2003) gives the same estimates of direct effects: testing for random covariates indicated that all the coefficients are the same, except for the constant term that has a significant variance- this fact is consistent with an effect of RDPD. Furthermore, the interaction term "RDPD and Older than 29" is not significant in a multi-level analysis.
} 
result is probably dominated by the influence of the U.S., a country with particularly high religiosity that we categorized as having a low level of Community Property.

We experimented with a dummy capturing whether a country has a catholic majority and with dummies for the year a country legalized abortions. In all of these estimations the RDPD variables continued to have an effect on $R$ similar to the one reported in Table 4. The RDPD effects dominated the effects of some related variables, in magnitude and level of significance.

\section{Conclusions}

The main purpose of this paper was to examine whether rules of division of couples' joint property (RDPD) affect the likelihood that women have an unpartnered birth. Based on a simple model assuming that women are rational and expect their potential male partner's earnings to exceed their own, we predicted that women would be more likely to have an unpartnered birth in common law countries and countries with separation of assets (which we classify as LC countries) than in countries with Community Property (MC and $\mathrm{HC}$ ). We also expected more unpartnered births in countries where Community Property includes a lower proportion of assets (MC countries) relative to countries considering more marital property as joint (HC--high community-countries). We find confirmation for these predictions based on two kinds of analyses of first births to women from twelve industrialized Western countries: pooled multi-country regressions and single-country regressions of change in legal regime.

We also find that RDPDs have less impact on unpartnered births among teenagers, women past age 29, and women growing up in a non-intact home. Also 
confirmed is our prediction that the effect of LC interacted with religiosity has the opposite sign as the sign of LC alone.

This exploratory economic analysis of the tie between unpartnered births and laws regulating division of joint property (RDPD) in case of divorce or separation could benefit from further work both at the theoretical and empirical level. Our study is based on a small number of countries and the magnitude of the coefficients of our RDPD dummies depends on the characteristics of each country included in our regressions.

We recommend that future cross-country comparisons include more variables, more countries, and more detailed analyses of legal differences. In particular, it would be useful to include information on each country’s welfare benefits and other indications of a country's generosity to mothers who are either single, cohabiting, or married. At first glance, degree of Community Property and welfare programs geared towards lone mothers don't seem to be positively correlated: most countries in our sample don't have welfare programs that are specifically geared towards lone mothers, except for two countries with diverging patterns of unpartnered births: the USA (which has a high prevalence of unpartnered births) and Sweden (with low prevalence of unpartnered births). These two countries are at opposite poles on our LC/HC scale. We hope that our findings will encourage others to perform single-country analyses similar to ours for other countries that have also experienced changes in legal regimes related to division of property at dissolution. 


\section{References}

Akerlof, George A., Janet L.Yellen, and Michael L. Katz, (1996). “An Analysis of Out-ofWedlock Childbearing in the United States.” Quarterly Journal of Economics 111: 277317.

Beck, Scott H., Bettie S. Cole, and Judith A Hammond, (1991)."Religious Heritage and Premarital Sex: Evidence from a National Sample of Young Adults." Journal for the Scientific Study of Religion 30 (2): 173-180.

Becker, Gary S. (1973). "A Theory of Marriage: Part I." Journal of Political Economy 81: 813-846.

(1981). A Treatise on the Family, 1st edition. Cambridge: Harvard University Press.

Blau, Francine D., Marianne A. Ferber, and Anne E. Winkler. (2006). The Economics of Women, Men, and Work. Fifth Edition. New Jersey: Pearson Prentice Hall.

Branas-Garza, Pablo and Shoshana Neuman (2007). "Parental Religiosity and Daughters' Fertility: The Case of Catholics in Southern Europe.” Review of Economics of the Household, forthcoming.

Choo, Eugene and Aloysius Siow (2006). "Who Marries Whom and Why." Journal of Political Economy 114(1) :175-201.

Dourleijn, Edith, Aat C. Liefbroer and Gijs C.N Beets (2002). Comparing the 1988 International Standard Classification of Education (ISCED) with Retrospective Information from Educational Histories in Martine Corijn and Erik Klijzing (eds.) Dynamics of Fertility and Partnership in Europe: Insights and Lessons from Comparative Research, Vol. II ; 157-172; New-York \& Geneva: United Nations.

Ekert-Jaffé, Olivia and Catherine Sofer (1996). "Formal Versus Informal Marriage: Explaining Factors." in Evolution or Revolution in European Population, vol. 2, EAPS, 65-85.

Ekert-Jaffé, Olivia and Anne Solaz (2001). "Unemployment, Marriage, and Cohabitation in France." Journal of Socio-Economics 30: 75-98.

Ekert-Jaffé Olivia, Heather Joshi, Kevin Lynch, Rémi Mougin, and Michael Rendall (2002)."Fertility, Timing of Births and Socio-economic Status in France and Britain”. Population (English) 7(3): 475-508.

Ermisch, John F. (1991). Lone Parenthood: an Economic Analysis ; xv, 194, National Institute of Economic and Social Research Occasional Papers, 44, Cambridge University Press.

Festy, Patrick and France Prioux (2002). "An Evaluation of the FFS Project: Comparability of the International Database." Economic Commission for Europe, Economic series, United Nations.

Furstenberg Frank. F.and Kathleen E Kiernan (2001). "Delayed Parental Divorce: How Much do Children Benefit ?” Journal of Marriage and the Family 63(2): 446-457.

Goldstein, Harvey ( 2003). Multilevel Statistical Methods, 3rd edition, Kendall’s Library 
of Statistics.

Grossbard, Shoshana (2005). “A Theory of Women’s Welfare Dependency, Marriage, and Labor Supply” Labour 19: 211-241.

Grossbard-Shechtman, Amyra (1982). "A Theory of Marriage Formality: The Case of Guatemala." Economic Development and Cultural Change 30: 813-30.

Grossbard-Shechtman, Amyra (1984). “A Theory of Allocation of Time in Markets for Labour and Marriage.” Economic Journal 94: 863-82.

Grossbard-Shechtman, Shoshana A. (1993). On the Economics of Marriage. Boulder, Co.: Westview Press.

Grossbard-Shechtman, Shoshana, Olivia Ekert-Jaffé, and Bertrand Lemennicier (2002). "Property Division at Divorce and Demographic Behavior." Paper presented at the American Economic Association, January.

Grossbard-Shechtman, Shoshana and Clive W.J. Granger (1998). "Women's Jobs and Marriage : Baby-Boom or Baby Bust.” Population 53: 731-52 (In French).

Guttentag, Marcia and Paul F. Secord (1983). Too Many Women: The Sex Ratio Question. Beverly Hills: Sage Publications.

Hawkes, Denise, Heather Joshi, and Kelly Ward (2004). Unequal Entry to Motherhood and Unequal Start to Life : Evidence from the First Survey of the UK Millennium Cohort. CLS Cohort Studies Working Paper $n^{\circ} .6$, London: Centre for Longitudinal Studies, Institute of Education.

Heer, David M. and Amyra Grossbard-Shechtman (1981). "The Impact of the Female Marriage Squeeze and the Contraceptive Revolution on Sex Roles and the Women's Liberation Movement in the United States, 1960 to 1975.” Journal of Marriage and the Family 43: 49-65.

Heuveline, Patrick, Jeffrey M. Timberlake., and Frank F Furstenberg Jr. (2003). "Shifting Childrearing to Single Mothers : Results from 17 Western Countries." Population and Development Review 29(1): 47-72.

Hobcraft John N. (1998) "Intergenerational and Life-Course Transmission of Social Exclusion: Influence of Child Poverty, Family Disruption, and Contact with Police” CASE Paper 1, ESRC Centre for Analysis of Social Exclusion, London School of Economics

Kiernan, Kathleen E. and Andrew J. Cherlin (1999). "Parental Divorce and Partnership Dissolution in Adulthood: Evidence from a British Cohort Study.” Population Studies $53(2)$ : 39-48.

Kirby, Douglas (1999). "Reflections on Two Decades of Research on Teen Sexual Behavior and Pregnancy.” Journal of School Health 69(3): 89-94.

Klepinger,Daniel H., Shelly Lundberg, and Robert Plotnick (1999). "How Does Adolescent Fertility Affect the Human Capital and Wages of Young Women?" Journal of Human Resources 34(3): 421-448. 
Lam, David (1988).”Marriage Markets and Assortative Mating with Household Public Goods : Theoretical Results and Empirical Implications.” Journal of Human Resources 23: 462-487.

Lehrer, Evelyn L. (2003). “The Economics of Divorce.” In Shoshana GrossbardShechtman, (ed.). Marriage and the Economy. Cambridge and New York: Cambridge University Press.

Lesthaeghe, Ron and Guy Moors (2000). "Recent Trends in Fertility and Household Formation in the Industrialized World." Review of Population and Social Policy 9: 121-170.

Lichter, Daniel T., Diane K. McLaughlin, George Kephart, and David J. Landry (1992). "Race and the Retreat from Marriage: A Shortage of Marriageable Men?" American Sociological Review 57 (December): 781-799.

McLanahan, Sara S. and Larry Bumpass (1988). "Intergenerational Consequences of Family Disruption." American Journal of Sociology 4 (July): 130-52.

McLanahan, Sara S. and Gary Sandefur (1994). Growing Up with a Single Parent: What Hurts, What Helps. Cambridge, Mass.: Harvard University Press.

McLanahan, Sara S. and Wendy Sigle-Rushton (2004). "Father Absence and Child Wellbeing: A Critical Review", in The Future of the Family. Moynihan, D.P., T.M. Smeeding, and L. Rainwater (eds.). New York, NY: Russell Sage Foundation.

Mincy, Ronald B., Shoshana Grossbard and Chien-Chung Huang (2005). “An Economic Analysis of Co-Parenting Choices: Single Parent, Visiting Father, Cohabitation, Marriage.” Paper presented at the European Society for Population Economics, Paris, June.

Mincy, Ronald B. and Helen Oliver (2003). "Age, Race, and Children's Living Arrangements: Implications for T.A.N.F. Reauthorization.” Washington, DC: The Urban Institute.

Moulton, Brent R. (1990) "An Illustration of a Pitfall in Estimating the Effects of Aggregate Variables on Micro Units". Review of Economics and Statistics 72: 334-38.

Murry, Velma McBride (1992). "Incidence of First Pregnancy among Black Adolescent Females Over Three Decades," Youth and Society 23 (4): 478-506.

Sigle-Rushton, Wendy, John Hobcraft, and Kathleen E. Kiernan (2005). "Parental Disruption and Adult Well-Being: A Cross Cohort Comparison.” Demography 42(3): 427-446.

Sweet, James A. and Larry L. Bumpass (1990). "Religious differentials in Marriage Behavior and Attitudes," NSFH Working Paper $n^{\circ}$. 15, University of Wisconsin.

Tapp P, (1981).”'The New Zealand Matrimonial Property Act 1976 “, Oxford Journal of Legal Studies 1: (3) 421-426.

Thornton, Arland and Donald Camburn (1989). "Religious Participation and Adolescent Sexual Behavior and Attitudes," Journal of Marriage and the Family 51 (August): 641-653. 
Vogel, Louis, ed. (2002). Juris-classeur de Droit Comparé. Paris: Michele Klein, Edition du Juris-classeur.

Willis Robert J. (1999). “A Theory of Out-of-Wedlock Childbearing.” Journal of Political Economy 107: S33-S64.

Wolfe, Barbara, Kathryn Wilson, and Robert Haveman (2001). "The Role of Economic Incentives in Teenage Nonmarital Childbearing Choices." Journal of Public Economics 81: 473-511. 
Table 1. Rule for Division of Marital Property in Case of Divorce and Percent Unpartnered First Births Among Women Born in 1945-1970

\begin{tabular}{|c|c|c|c|}
\hline $\begin{array}{l}\text { Country and } \\
\text { Year of Survey } \\
\end{array}$ & $\begin{array}{l}\text { Rule for Division of } \\
\text { Marital Property }\end{array}$ & $\begin{array}{c}\text { Degree of } \\
\text { Community } \\
\end{array}$ & $\begin{array}{c}\text { Percent of } \\
\text { Unpartnered } \\
\text { First Births }^{\text {a }} \\
\end{array}$ \\
\hline $\begin{array}{l}\text { New Zealand } \\
1995\end{array}$ & $\begin{array}{l}\text { Common Law before and } \\
\text { Acquired Assets after } \\
1976\end{array}$ & LOW/MEDIUM & 11 \\
\hline $\begin{array}{l}\text { USA } \\
1995\end{array}$ & Common Law & LOW & 15 \\
\hline $\begin{array}{l}\text { Canada }^{\mathrm{b}} \\
1995\end{array}$ & Common Law & LOW & 19 \\
\hline $\begin{array}{c}{\text { Quebec }+ \text { Ontario }^{\mathrm{c}}} \\
1995 \\
\end{array}$ & Acquired Assets ${ }^{\mathrm{d}}$ & MEDIUM & 11 \\
\hline $\begin{array}{c}\text { Austria } \\
1995\end{array}$ & Some Acquired Assets & LOW & 20 \\
\hline $\begin{array}{c}\text { Germany } \\
1992 \\
\end{array}$ & Acquired Assets & MEDIUM & 11 \\
\hline $\begin{array}{c}\text { Belgium } \\
\text { (Flanders) } \\
1992 \\
\end{array}$ & Acquired Assets ${ }^{\mathrm{d}}$ & MEDIUM & 3 \\
\hline $\begin{array}{c}\text { France } \\
1994\end{array}$ & Acquired Assets ${ }^{d}$ & MEDIUM & 7 \\
\hline $\begin{array}{c}\text { Finland } \\
1990 \\
\end{array}$ & $\begin{array}{c}\text { Acquired Assets / } \\
\text { Unrestricted Community e }\end{array}$ & MEDIUM & 10 \\
\hline $\begin{array}{c}\text { Norway } \\
1989\end{array}$ & Unrestricted Community ${ }^{\mathrm{e}}$ & HIGH & 13 \\
\hline $\begin{array}{c}\text { Sweden } \\
1993\end{array}$ & Unrestricted Community ${ }^{\mathrm{e}}$ & HIGH & 8 \\
\hline $\begin{array}{c}\text { Italy } \\
1995 / 6\end{array}$ & $\begin{array}{c}\text { No divorce/ Acquired } \\
\text { Assets }{ }^{\mathrm{f}}\end{array}$ & $\begin{array}{c}\text { No } \\
\text { divorce/MEDIUM } \\
\end{array}$ & 4 \\
\hline $\begin{array}{l}\text { Spain } \\
1995\end{array}$ & $\begin{array}{c}\text { No divorce/ Acquired } \\
\text { Assets }{ }^{\mathrm{f}}\end{array}$ & $\begin{array}{c}\text { No } \\
\text { divorce/MEDIUM }\end{array}$ & 4 \\
\hline
\end{tabular}

Notes: a) Unpartnered status observed three months before birth; mothers born in 19461970 giving birth in 1962-1992; b) Excludes Quebec for the entire period and Ontario after 1978; c) Ontario: for births after 1985; d) Community property only for assets acquired during the marriage; e) Community property is unrestricted: includes assets acquired before and after marriage; f) Acquired Assets from 1975 in Italy and from 1981 in most of Spain; before these dates, separation of assets in rare cases of marriage annulment. 


\section{Table 2: Predicted Effects on Unpartnered Births}

\begin{tabular}{|l|c|}
\hline Variable & Predicted Effect on Unpartnered Birth \\
\hline Aggregate Variables: & \\
\hline Rule for Division of Property at Divorce & + \\
\hline Low degree of Community Property (LC) & - \\
\hline High degree of Community Property (HC) & + \\
\hline Mother's Personal Characteristics: & + \\
\hline Teenage mother & + \\
\hline Mother comes from a Non-Intact (NI) family & \\
\hline Interactions & + \\
\hline Teenager in LC country & + \\
\hline Teenager in HC country & \\
\hline Observant of religion in LC country & $\begin{array}{c}\text { Sign in opposite direction than the } \\
\text { main effect of religious observance }\end{array}$ \\
\hline Observant of religion in HC country & $\begin{array}{c}\text { Sign same as the sign of the main } \\
\text { effect of religious observance }\end{array}$ \\
\hline
\end{tabular}


Table 3. Women's Characteristics Prior to their First Child's Birth

\begin{tabular}{|c|c|c|c|c|c|c|c|c|c|c|c|c|c|c|}
\hline & Austria & $\begin{array}{c}\text { New } \\
\text { Zealand }\end{array}$ & USA & Canada & $\begin{array}{l}\text { Belgium: } \\
\text { Flanders }\end{array}$ & France & $\begin{array}{c}\text { West } \\
\text { Germany }\end{array}$ & Italy & Spain & Finland & Norway & Sweden & $\begin{array}{c}\text { All } 12 \\
\text { Countries }\end{array}$ & $\begin{array}{l}\text { Total } 7 \\
\text { Countries }\end{array}$ \\
\hline Year of Survey & 1995 & 1995 & 1995 & 1995 & 1992 & 1994 & 1992 & 1996 & 1995 & 1990 & 1989 & 1993 & & \\
\hline $\begin{array}{l}\text { Sample size } \\
\text { Birth Cohort and Period }\end{array}$ & 2923 & 1873 & 6274 & 2252 & 1983 & 2111 & 1352 & 2826 & 2486 & 3038 & 2457 & 2316 & 31891 & 21215 \\
\hline Mother born 1946-50 (\%) & 22 & 22 & 3 & 22 & 0 & 26 & 0 & 21 & 19 & 34 & 43 & 27 & 20 & 17 \\
\hline $\begin{array}{l}\text { Mean Child's Year of Birth } \\
\text { Age at First Birth }\end{array}$ & 80 & 80 & 82 & 81 & 81 & 79 & 83 & 80 & 81 & 77 & 76 & 80 & 81 & 81 \\
\hline Mean Age & 22 & 23 & 23 & 24 & 23 & 23 & 23 & 24 & 24 & 24 & 22 & 23 & 23.6 & 23.6 \\
\hline Variance & 17 & 21 & 23 & 23 & 11 & 18 & 15 & 20 & 18 & 19 & 15 & 19 & 19.4 & 20.7 \\
\hline$>29 \quad(\%)$ & 7 & 11 & 11 & 15 & 4 & 8 & 6 & 11 & 9 & 10 & 6 & 11 & 10 & 10 \\
\hline$<20 \quad(\%)$ & 21 & 17 & 27 & 10 & 10 & 15 & 17 & 13 & 10 & 14 & 21 & 14 & 18 & 19 \\
\hline Parents are Divorced (\%) & 11 & $\cdot$ & 24 & 17 & 7 & 11 & 10 & 2 & 4 & 7 & $\cdot$ & 13 & & 12 \\
\hline Religiously Observant (\%) & 21 & $\cdot$ & 38 & 21 & . & . & 11 & 34 & 20 & 4 & 5 & 4 & & 22 \\
\hline $\begin{array}{l}1,2 \text { or } 3 \text { Siblings }(\%) \\
\text { Education before pregnancy }\end{array}$ & 65 & 58 & 55 & 53 & 59 & . & 70 & 65 & 57 & 57 & 71 & 72 & & 62 \\
\hline High School or less (\%) & 88 & . & 74 & . & 78 & 81 & 73 & 74 & 84 & 71 & 79 & 75 & & 77 \\
\hline College (\%) & 8 & . & 17 & . & 24 & 10 & 19 & 5 & 8 & 17 & 16 & 11 & & 13 \\
\hline $\begin{array}{l}\text { More than College (\%) } \\
\text { Occupational Status } \\
\underline{\text { Before pregnancy }}\end{array}$ & 4 & . & 9 & . & 4 & 9 & 8 & 11 & 8 & 12 & 5 & 14 & & 10 \\
\hline In School (\%) & 10 & · & 8 & . & 3 & 4 & 10 & 5 & 7 & 19 & 7 & 14 & & 10 \\
\hline In Employment (\%) & 64 & & 35 & & 51 & & 61 & 27 & 34 & 62 & 63 & 65 & & 47 \\
\hline Out of Labor Force (\%) & 26 & & 57 & & 45 & & 28 & 67 & 58 & 17 & 29 & 20 & & 43 \\
\hline
\end{tabular}


Table 4. Pooled Logit Regressions of Proportion of Unpartenered Births; Partnership Measured 3 Months Prior to Birth

\begin{tabular}{|c|c|c|c|c|c|c|}
\hline \multirow[b]{2}{*}{ Variables } & \multicolumn{3}{|c|}{ Basic model } & \multicolumn{3}{|c|}{ Model including socio-economic variables ${ }^{\text {b }}$} \\
\hline & $\begin{array}{c}12 \text { countries/17 RDJP } \\
\text { a } \\
(1) \\
\end{array}$ & $\begin{array}{c}10 \text { countries/14 RDJP } \\
(2) \\
\end{array}$ & $\begin{array}{l}7 \text { countries/9 RDJP } \\
\text { (3) }\end{array}$ & $\begin{array}{l}10 \text { countries/14 RDJP } \\
(4) \\
\end{array}$ & $\begin{array}{c}8 \text { countries/12 RDJP } \\
\text { (5) }\end{array}$ & $\begin{array}{l}7 \text { countries/9 RDJP } \\
(6) \\
\end{array}$ \\
\hline $\begin{array}{l}\text { Intercept } \\
\text { Macro Factors } \\
\text { Rule for Division of Joint Property (RDJP) }\end{array}$ & $0.7114(0.52)$ & $0.8217(0.59)$ & $1.495^{* *}(0.73)$ & $0.8467(0.60)$ & $1.374(0.58)$ & $1.097 * *(0.61)$ \\
\hline Low Community Property (LC) & $\mathbf{0 . 7 0 2}(0.239)$ & $0.7791(0.249)$ & $\mathbf{0 . 6 5 9 0}(0.272)$ & $\mathbf{0 . 8 1 7 4}(0.260)$ & $\mathbf{0 . 5 0 7 1}(0.213)$ & $0.5435(0.208)$ \\
\hline High (HC) & $0.005(0.241)$ & $-0.2583(0.176)$ & $-0.3507 *(0.190)$ & $-0.288 *(0.169)$ & $-0.4662(0.144)$ & $-0.3576(0.145)$ \\
\hline Divorce Prohibited & $-\mathbf{0 .} 841(0.228)$ & $\mathbf{- 0 . 8 4 0 7}(0.230)$ & $-0.9693(0.250)$ & $-\mathbf{0 . 8 2 2 1}(0.235)$ & $-\mathbf{0 . 9 6 0 1}(0.244)$ & $\mathbf{- 0 . 8 3 7 3}(0.271)$ \\
\hline Cohort and Period & & & & & & \\
\hline Mother Born in $1946-52$ & $\mathbf{0 . 4 8 4}(0.108)$ & $0.5438(0.125)$ & $\mathbf{0 . 4 7 9 7}(0.131)$ & $0.5376(0.126)$ & $0.4677(0.123)$ & $\mathbf{0 . 4 5 2 6}(0.133)$ \\
\hline Trend : Child's Year of Birth & $\mathbf{0 . 0 2 2}(0.007)$ & $0.0189 * *(0.008)$ & $0.0087(.0100)$ & $0.0172 * *(0.007)$ & $0.0129 *(0.008)$ & $0.010(0.009)$ \\
\hline $\begin{array}{l}\text { Women's Characteristics } \\
\text { Age at First Birth and Interactions with } \\
\underline{\text { RDJP }}\end{array}$ & & & & & & \\
\hline Age & $-0.2377(0.017)$ & $-0.2302(0.018)$ & $-0.2183(0.020)$ & $-0.2273(0.018)$ & $-\mathbf{0 . 2 2 4 2}(0.017)$ & $\mathbf{- 0 . 1 9 9 5}(0.209)$ \\
\hline (Age-23) Square & $\mathbf{0 . 0 1 4 1}(0.001)$ & $\mathbf{0 . 0 1 3 1}(0.013)$ & $\mathbf{0 . 0 1 1 8}(0.001)$ & $\mathbf{0 . 0 1 3 0}(0.001)$ & $0.0123(0.001)$ & $0.0118(0.001)$ \\
\hline Older than 29 & $0.5908(0.173)$ & $\mathbf{0 . 6 8 7 7}(0.176$ & $0.6751(0.224)$ & $\mathbf{0 . 6 9 6 6}(0.176)$ & $0.6395(0.208)$ & $\mathbf{0 . 6 5 4 7}(0.254)$ \\
\hline Younger than 20 in a HC Country & $0.5903(0.111)$ & $0.7340(0.077)$ & $0.7490(0.097)$ & $0.7472(0.076)$ & $0.7350(0.077)$ & $0.7063(0.100)$ \\
\hline Older than 29 in a LC Country & $0.5533(0.140)$ & $-0.6493(0.114)$ & $-0.5526(0.132)$ & $-\mathbf{0 . 6 6 3 2}(0.114)$ & - $0.5470(0.110)$ & $-0.5711(0.127)$ \\
\hline Family of Origin and RDJP & & & & & & \\
\hline Non-intact Family of Origin & & & & $0.4467(0.121)$ & $0.3323(0.117)$ & $0.2526(0.099)$ \\
\hline Non-intact in a LC Country & & & & $\mathbf{- 0 . 3 8 4 5}(0.133)$ & $-0.2409 *(0.129)$ & $-0.1230(0.111)$ \\
\hline Religious Observance and RDJP & & & & & & \\
\hline Observant & & & & & $-0.4228 * *(0.210)$ & $-0.5292(0.150)$ \\
\hline Observant in a LC Country & & & & & $0.5763^{* *}(0.268)$ & $0.7383(0.148)$ \\
\hline Number of Siblings Between 1 and 3 & & & & & & $-\mathbf{0 . 1 6 5 1}(0.052)$ \\
\hline Education & & & & & & \\
\hline Education: Some College & & & & & & $-0.3632 * *(0.17)$ \\
\hline Education :More than College & & & & & & $-\mathbf{0 . 5 1 5 8}(0.16)$ \\
\hline Occupational Status Prior to Pregnancy & & & & & & \\
\hline In School & & & & & & $\mathbf{0 . 5 3 9 8}(0.060)$ \\
\hline Out of Labour Force and not in School & & & & & & $-0.7774(0.078)$ \\
\hline Sample Size & 31449 & 27119 & 20933 & 27119 & 23467 & 20933 \\
\hline Log (Pseudo-Likelihood ) & -7914 & -7915 & -6391 & -7903 & -7148 & -6334 \\
\hline
\end{tabular}

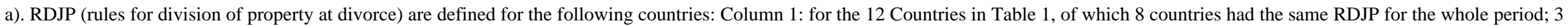

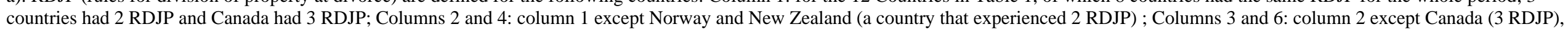

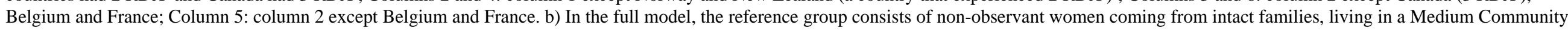

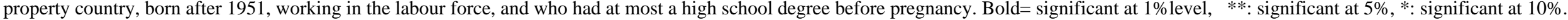


Table 5. Proportion of Out-of-Couple Births: Pooled Logit Regressions; Partnership Measured at Birth

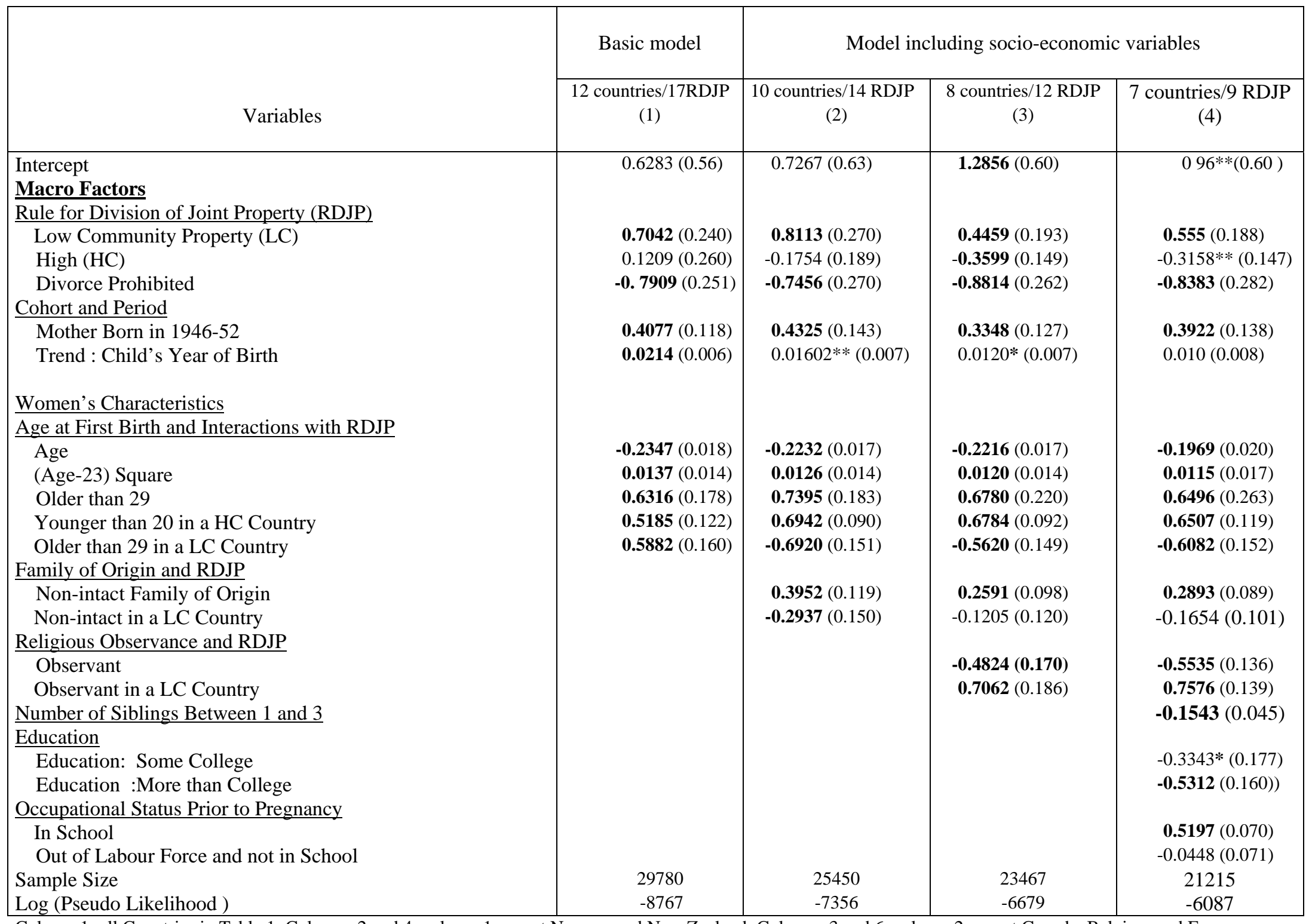

Column 1: all Countries in Table 1; Columns 2 and 4: column 1 except Norway and New Zealand; Columns 3 and 6: column 2 except Canada, Belgium and France;

Column 5: column 2 except Belgium and France.

Bold= significant at $1 \%$ level, **: significant at 5\%, *: significant at $10 \%$. 
Table 6 : Single Country Regressions of the Effect of Previous Rule on Unpartnered Births: Ontario (Canada), New Zealand, Spain and Italy.

\begin{tabular}{|c|c|c|c|c|}
\hline Variables & $\begin{array}{l}\text { Province of } \\
\text { Ontario, Canada }\end{array}$ & New Zealand & Spain & Italy \\
\hline Intercept & $\begin{array}{c}-0.7426^{24} \\
(2.30)\end{array}$ & $\begin{array}{l}-3.9682 \\
(3.801)\end{array}$ & $\begin{array}{l}1.9036 \\
(3.050)\end{array}$ & $\begin{array}{c}24.7658 \\
(8.956)\end{array}$ \\
\hline Previous Rule: Common Law (LC) & $\begin{array}{l}1.1130 \\
(0.437)\end{array}$ & $\begin{array}{l}1.4046 \\
(0.538)\end{array}$ & & \\
\hline Previous Rule: No Divorce & & & $\begin{array}{l}\mathbf{- 1 . 0 8 4 4} \\
(0.468)\end{array}$ & $\begin{array}{l}-2.7936 \\
(1.055)\end{array}$ \\
\hline Trend : Child’s Year of Birth & $\begin{array}{c}0.0551 * \\
(0.031)\end{array}$ & $\begin{array}{l}0.1041^{* *} \\
(0.047)\end{array}$ & $\begin{array}{l}-0.0119 \\
(0.036)\end{array}$ & $\begin{array}{r}-\mathbf{0 . 3 5 9 2} \\
(0.116)\end{array}$ \\
\hline Age of the mother at child's birth & $\begin{array}{l}\mathbf{- 0 . 2 6 0 4} \\
(0.036)\end{array}$ & $\begin{array}{l}\mathbf{- 0 . 3 4 7 0} \\
(0.042)\end{array}$ & $\begin{array}{l}\mathbf{- 0 . 1 7 2 7} \\
(0.029)\end{array}$ & \\
\hline (Age -mean age at birth) Square & $\begin{array}{l}\mathbf{0 . 0 1 6 1} \\
(0.005)\end{array}$ & $\begin{array}{c}\mathbf{0 . 0 3 7 4} \\
(0.0054)\end{array}$ & $\begin{array}{c}\mathbf{0 . 0 1 4 3} \\
(0.0042)\end{array}$ & \\
\hline $\begin{array}{l}\text { Younger than } 20 \text { and Low } \\
\text { Community }\end{array}$ & & $\begin{array}{c}-0.7837^{*} \\
(0.424)\end{array}$ & & \\
\hline $\begin{array}{l}\text { Younger than } 20 \text { and Divorce } \\
\text { Prohibited }\end{array}$ & & & $\begin{array}{c}0.7329 * \\
(0.450)\end{array}$ & \\
\hline Education : Some College & & & & $\begin{array}{l}2.0919 \\
(0.646)\end{array}$ \\
\hline Log.Likelihood Ratio & 79 & 155 & 77 & 16 \\
\hline Sample Size & 404 & 947 & 2141 & 575 \\
\hline -2 Log Likelihood & 462 & 450 & 673 & 248 \\
\hline $\begin{array}{l}\text { Children Born in the Years } \\
\text { Year Law Changed }\end{array}$ & $\begin{array}{c}1966-1991 \\
1978\end{array}$ & $\begin{array}{c}1966-1985 \\
1976\end{array}$ & $\begin{array}{c}1970-1991 \\
1981\end{array}$ & $\begin{array}{c}1966-71 \text { and } \\
1975-80^{25} \\
1971\end{array}$ \\
\hline
\end{tabular}

\footnotetext{
${ }^{24}$ Standard errors in parentheses

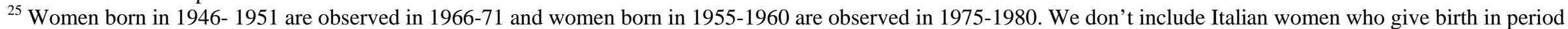
1972-1974, a period of transition between the passage of a divorce law (December 1970) and a law regarding division of property at divorce in 1975.
} 